\title{
Effect of carcass model on maggot distribution and thermal generation of two forensically important blowfly species, Chrysomya megacephala (Fabricius) and Chrysomya rufifacies (Macquart)
}

\author{
Azwandi Ahmad ${ }^{1 *}$ (D) and Baharudin $\mathrm{Omar}^{2}$
}

\begin{abstract}
Background: At feeding stage, blowfly larvae (Diptera: Calliphoridae) form aggregation to facilitate the breakdown of a human body after death. The aggregation structure of blowfly larvae could probably be different depending on fly species and food size. In forensic investigations, corpse size does not only affect the internal temperature after death, but it could also potentially influence the distribution, aggregation temperature, and species of flies that inhabit a corpse. However, there is no reference available to explain how these factors could affect maggot distribution pattern and thermal generation. The best way to answer this is by accessing blowfly aggregation on multiple forensic entomology animal models of different sizes. Thus, this research is a preliminary assessment to determine maggot aggregation structure and its thermal generation in three carcass species which are commonly used as a surrogate for human corpses in Malaysia.
\end{abstract}

Methodology: Frequency of Chrysomya megacephala (Fabricius) and Chrysomya rufifacies (Macquart) aggregations at a different location in carcass was determined. Aggregation temperature, depth, perimeter, area, and volume of tightly packed aggregations were measured. These variables were compared to ambient temperature and relative humidity. Correlation analysis was performed to access any relationship between each variable.

Results: Aggregation temperature was found strongly correlated to carcass temperature $(r=0.65, p<0.05)$, moderately correlated to carcass ground temperature $(r=0.57, p<0.05)$, and weakly correlated to aggregation depth $(r=0.21$, $p<0.05)$, relative humidity $(r=0.06, p=0.35)$, and ambient temperature $(r=0.01, p=0.89)$. The rate of carcass loss was significantly influenced by carcass model $(p<0.05)$. The frequency of Chrysomya megacephala (Fabricius) (Diptera: Calliphoridae) aggregation was more in rat carcasses, while for rabbits and macaques, Chrysomya rufifacies (Macquart) (Diptera: Calliphoridae) was more frequent. Aggregations of Chrysomya rufifacies were frequently observed located below carcasses while Chrysomya megacephala were observed mostly in the mouth and genitalia. Chrysomya rufifacies aggregations have produced higher temperature compared to Chrysomya megacephala.

(Continued on next page)

\footnotetext{
*Correspondence: azwandi2012@gmail.com

'Faculty of Pharmacy, Universiti Teknologi MARA, 42300 Bandar Puncak Alam,

Selangor, Malaysia

Full list of author information is available at the end of the article
} 


\begin{abstract}
(Continued from previous page)
Conclusion: Carcass model was proven to be a critical factor in larval aggregation distribution and temperature.

Therefore, this preliminary study has pointed out the necessity of proper selection of animal model for forensic

entomology study. Food source characteristics, particularly body size, could play a significant factor in larval

aggregation distribution and thermal generation, therefore making this factor important when making postmortem

interval (PMI) estimation based on larval growth.
\end{abstract}

Keywords: Carcass, Maggot mass, Postmortem Interval , Aggregation, Chrysomya megacephala, Chrysomya rufifacies

\section{Background}

The concept of accumulated degree hours (ADH) has been used to optimize the timing of insecticide applications to control agricultural pest which is based on the temperature-dependent rate of development of coldblooded insects. In forensic entomology, this concept has been used to estimate the time of death by utilizing blowfly larva developmental records. In a laboratory, a total number of hours multiplied by temperature is used to determine the total ADH of a blowfly development. However, as ADH has been widely used, a problem arises due to the unknown thermal history of larva development. Researchers indicated that the ADH could be miscalculated when it is not referred to heat produced by the larvae within a maggot aggregation (Peters 2003; Slone and Gruner 2007). A previous finding showed that the actual temperature at which maggot develops is unknown, as maggots are continually moving down to the feeding site then back out to the exterior of the aggregation (Anderson and VanLaerhoven 1996). Moreover, the maggot aggregation temperature can remain high regardless of daily weather fluctuation. It was reported that maggot mass temperature could reach $16.7^{\circ} \mathrm{C}$ above ambient temperature in a pig exposed to the sun in summer and slightly lower, $11.4^{\circ} \mathrm{C}$ above ambient, in a pig in shade (Shean et al. 1993). A study also noted that heat can be higher, reaching $32^{\circ} \mathrm{C}$ above ambient temperature (Turner and Howard 1992). Due to this thermal generation, a question has been raised whether postmortem interval (PMI) calculation based on surrounding temperature (usually obtained from the nearest weather station) is accurate and reliable. Therefore, a number of studies have emphasized on fly larval aggregation (Byrd and Butler 1998; Campobasso et al. 2001; Goff 2000; Greenberg 1991; Greenberg and Kunich 2002; Hewadikaram and Goff 1991; Joy et al. 2002). However, there are very few studies have accessed the larval aggregation formation in carcass exposed in a surrounding natural condition (Slone and Gruner 2007). Therefore, this research was carried out to extend knowledge on the distribution and thermal generation of blowfly aggregation in a surrounding natural environment using three common forensic entomology animal models which were laboratory rats, domestic rabbits, and long-tailed macaque. These models are standard and have been a surrogate to human cadaver in forensic entomology study in Malaysia (Azwandi and Abu Hassan 2009; Zuha et al. 2016; Rumiza et al. 2008).

\section{Methods}

\section{Location and study duration}

The study was conducted in the Forensic Science Simulation site at Universiti Kebangsaan Malaysia, Bangi, Selangor, Malaysia (West of Malaysia Peninsular: $2.9^{\circ} \mathrm{N}$, $101.8^{\circ} \mathrm{E}$, at an altitude of $42 \mathrm{~m}$ above sea level). This site is a protected area and has been used for many decomposition studies in the previous years. The carcass placement site is a shaded secondary forest which received moderate sunlight. Common scavengers in the study area are domestic dogs, cobras (Naja naja), and monitor lizards (Varanus salvator). The duration of the study was two years, from 13 November 2009 until 8 June 2011.

\section{Animal model}

Three species of carcasses were used in the study: laboratory rats (Rattus norvegicus, mean weight $0.508 \mathrm{~kg}$ ), domestic rabbits (Oryctolagus cuniculus, mean weight $2.538 \mathrm{~kg}$ ), and wild macaque (Macaque fascicularis, mean weight $5.750 \mathrm{~kg}$ ). The weight ratio of those carcasses was 1:5:11. Laboratory rats and domestic rabbits were obtained from Animal House Facility, Faculty of Medicine, Universiti Kebangsaan Malaysia, while wild macaque was provided by the Department of Wildlife Wilayah Persekutuan (PERHILITAN). Before carcass placement, all animals were euthanized by intravenous injection of sodium pentobarbital (Dorminal ${ }^{\circ}$ ). Killing procedure fulfilled the animal ethics guidelines as approved by the Animal Ethics Committee, Faculty of Medicine, Universiti Kebangsaan Malaysia (UKMAEC No: FSKB/ 2010/Baharudin/17-March/297-March-2010-April-2012).

During this period, a total of 12 rats, 12 rabbits, and 12 macaques were used. Due to a large number of carcasses, the study was conducted in four rounds. Details of each round and the number of carcasses used in each round are shown in Table 1 . For each round, the carcasses were placed in 1 in. $\times 2$ in. gauge wire mesh cage. Each cage was embedded 4 in. into the ground to prevent potential 
Table 1 Number of animals used in each round of the experiment

\begin{tabular}{llllll}
\hline Animal & Exp1 & Exp 2 & Exp 3 & Exp 4 & Total \\
\hline Laboratory rat (mean $0.51 \mathrm{~kg})$ & 4 & 4 & 4 & - & 12 \\
Domestic rabbit (mean $2.54 \mathrm{~kg})$ & 4 & - & 4 & 4 & 12 \\
Macaque (mean $5.75 \mathrm{~kg}$ ) & 4 & 4 & - & 4 & 12 \\
\hline
\end{tabular}

carcass movement by a scavenger. For weighing purposes, a wire mesh platform was placed below each carcass. The cages were positioned at a 15-m distance each, and the arrangement of each carcass was made randomly.

\section{Environmental data collection}

Weather data were recorded using electronic weather station (EasyWeather ${ }^{\circ}$ ) placed at a clear compound near to the study area. The weather station was set up to record data every $5 \mathrm{~min}$ from day 0 to day 14 and hourly afterward. For a backup, an electronic temperature-humidity logger was placed in the forest near to the carcasses' location. For measuring carcass temperature, temperature loggers with the K-type probe were used. Each of them was inserted into the rectum of the carcasses.

\section{Maggot mass observation and measurement}

The carcasses were visited twice a day at 1100 and 1600 from the day of placement to day 5 and only once afterwards. Only a tightly packed aggregation with a clear boundary was included for counting and measurement. Maggot mass temperature measurements were done by gently inserting the warmed stainless steel part of the digital thermometer (Hanna Instruments ${ }^{\oplus}$ ) into five locations in the aggregation. Meanwhile, five readings of maggot aggregation surface temperatures were recorded using an infrared thermometer (IR thermometer). A modified ruler was used to collect five depth readings from selected maggot mass. For computer analysis, maggot mass image was captured using a high-resolution digital camera setting (Canon PowerShot G11). Images of each larval aggregation were then processed using DimasExpert ${ }^{\oplus}$ software. This software was used to measure the area and perimeter of each aggregation. In each selected aggregation, 15 larvae were randomly collected and placed in a screw cap vial. Aggregations were grouped into six location categories named as the mouth, genitalia, abdomen, under carcass, away, and other sites. Carcasses were weighed after most of the third instar larvae have migrated to measure the rate of larva feeding activities.

\section{Species identification}

Fifteen larvae from each vial which were collected during field visit were transferred in a feeding pouch made from aluminum foil. This pouch was made by folding a 6 in. $\times 7$ in. piece of aluminum foil. A small portion of moisture beef liver was then placed in the pouch. The pouch opening was covered with wet tissue and transferred into a plastic container half-filled with sawdust. At a random point during rearing time, one third instar larva from each container was sampled, dissected, and identified using a larval taxonomic key (Omar 2002). The remaining larvae were left to develop until adult stage. Emerged adult flies were collected and identified using an adult Diptera taxonomic key (Kurahashi et al. 1997). Based on the identification, no other fly family other than Calliphoridae was found, confirming that the observed aggregation in carcass belonged to Calliphorids flies either Chrysomya megacephala or Chrysomya. rufifacies.

\section{Data analysis}

Larva mass area and perimeter were measured using DimasExpert ${ }^{\oplus}$ software. To obtain the volume of the maggot mass, we multiplied the area of the aggregation by the mean of the five depth measurements recorded on the data sheet. For statistical analysis, data were analyzed using Statistical Package for Social Sciences (SPSS) version 16.

\section{Results}

In all carcass models, two blowfly species Ch. megacephala (Fabricius) and Ch. rufifacies (Macquart) were dominant, and their larva formed solid aggregations; therefore, making the examination of their aggregation parameters is possible. Adult Chrysomya nigripes (Aubertin), Chrysomya chani (Kurahashi), and Chrysomya villeneuvi (Patton) were also observed, but they did not form a clear aggregation and were unsuitable for examination. Thus, they were excluded from sampling and measurement. A total of 260 aggregations were included in the analyses which were obtained from those four rounds of experiment.

In the study, there was no difference in average temperature and relative humidity between each round of experiment, $F(3,122)=1.09, p=0.357, \eta^{2}=0.744$. Based on continuous temperature measurement during decomposition, carcass temperature in the rectum started to elevate at two points, the first point at $20 \mathrm{~h}$ while the second point at $45 \mathrm{~h}$ (Fig. 1). The first elevation took place for only $10 \mathrm{~h}$ while the second elevation was longer and unique to carcass model. In the second elevation, rabbit and macaque carcasses were able to prolong temperature elevation until $83 \mathrm{~h}$ and $95 \mathrm{~h}$ respectively. Recorded maximum body temperature for rabbit was $37^{\circ} \mathrm{C}$ while for macaque carcass was $40{ }^{\circ} \mathrm{C}$. However, in rat carcass, the highest body temperature recorded was not more than $28^{\circ} \mathrm{C}$.

Our analysis indicated that rate of carcass weight loss after 6 days of decomposition was varied based on the 


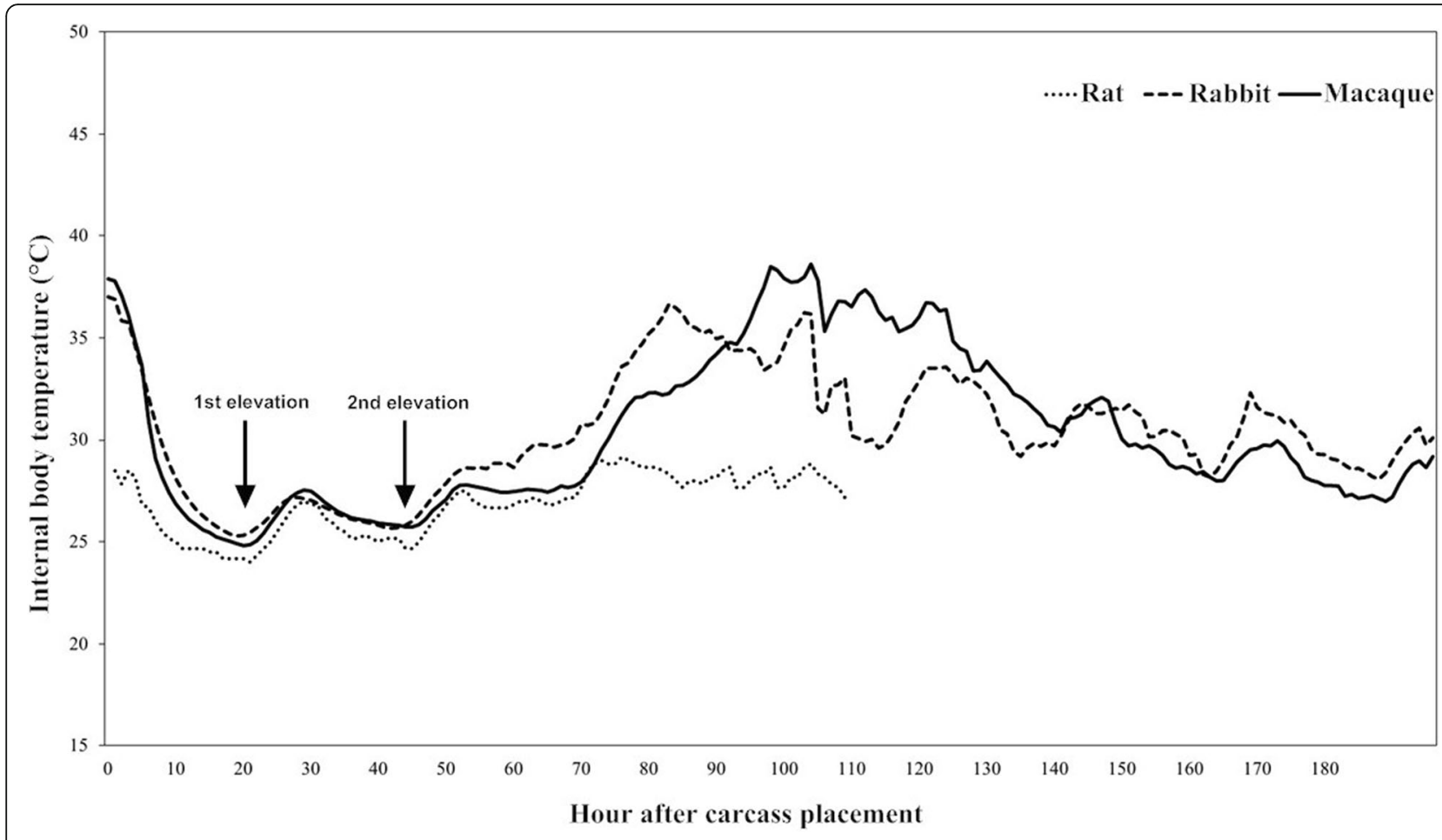

Fig. 1 Data logger reading of hourly body temperature $\left({ }^{\circ} \mathrm{C}\right)$ showing two elevation points in rat, rabbit, and macaque carcasses

animal model used $F(2,23)=33.513, p=0.001, \eta^{2}=$ 0.744 . Multiple comparisons by Tukey HSD showed that weight loss in monkey carcasses $(M=0.789, S D=0.130)$ was significantly higher than that in rat $(M=0.526, S D$ $=0.081)$ and rabbit carcasses $(M=0.589, S D=0.069)$.

Distribution and frequency of each observed larval aggregation are shown in Table 2. Larval aggregation analysis indicated that $\mathrm{Ch}$. megacephala was more associated with smaller carcasses. Twenty-three aggregations of this species were found in rat carcasses while only 7 and 14 in rabbit and monkey carcasses, respectively. $C h$. rufifacies larvae dominated rabbit and monkey carcass with 85 and 113 aggregations, respectively. Records have shown that only 18 aggregations were found in rat carcasses. With regards to location, most of the aggregations of Ch. rufifacies were located below carcasses while
Ch. megacephala aggregations were located mostly in the mouth and genitalia. The highest number of aggregations (42 aggregations) was by $C h$. rufifacies which was located under macaque carcasses with a measured temperature of $44.1^{\circ} \mathrm{C}$. Most of the Ch. megacephala aggregation temperature was lower than that of Ch. rufifacies. In some carcass visits, we found that Ch. rufifacies and Ch. megacephala could form species-specific aggregation which was separated by a clear boundary (Fig. 2). Duration of this species-specific aggregation had taken place for only 1 day. It was then ceased followed by overwhelmed mass of Ch. rufifacies.

A strong correlation of aggregation temperature with carcass temperatures, $r(188)=0.65, p<0.01$ was found (Fig. 3). We also noted that the highest aggregation temperature occurred concurrently with the onset of third

Table 2 Number of aggregation at five different locations in carcasses

\begin{tabular}{llllllll}
\hline Carcass & Blowfly species & Mouth & Genitalia & Under carcass & Abdomen & Away from carcass & Other \\
\hline Rat & Ch. megacephala & $1(29.9)$ & $8(28-31.1)$ & $2(31)$ & $7(27.9-33.4)$ & $4(29.1-31.7)$ & $1(28.4)$ \\
& Ch. rufifacies & $3(26.4-27.4)$ & $2(29.6-30.5)$ & $2(26.1-30.6)$ & 0 & $11(26.7-33.2)$ & 0 \\
Rabbit & Ch. megacephala & $4(30.5-31.1)$ & $1(31.9)$ & 0 & $2(34.5-34.5)$ & 0 & 0 \\
& Ch. rufifacies & $9(35.7-40.6)$ & $18(32.7-41.7)$ & $34(29.1-37.6)$ & $11(31-39.7)$ & $13(29.7-38.4)$ & 0 \\
Macaque & Ch. megacephala & $8(29-39)$ & $2(30.5-32.6)$ & 0 & 0 & $2(33.3-37.2)$ & $2(35.2-35.2)$ \\
& Ch. rufifacies & $12(32.4-40.4)$ & $17(32.6-41.6)$ & $42(26-44.1)$ & $28(29.1-41.9)$ & $11(32.3-40.8)$ & $3(40.1-40.1)$ \\
Total & & 37 & 48 & 80 & 48 & 41 & 6 \\
\hline
\end{tabular}

Values in parenthesis are temperature range in ${ }^{\circ} \mathrm{C}$ 


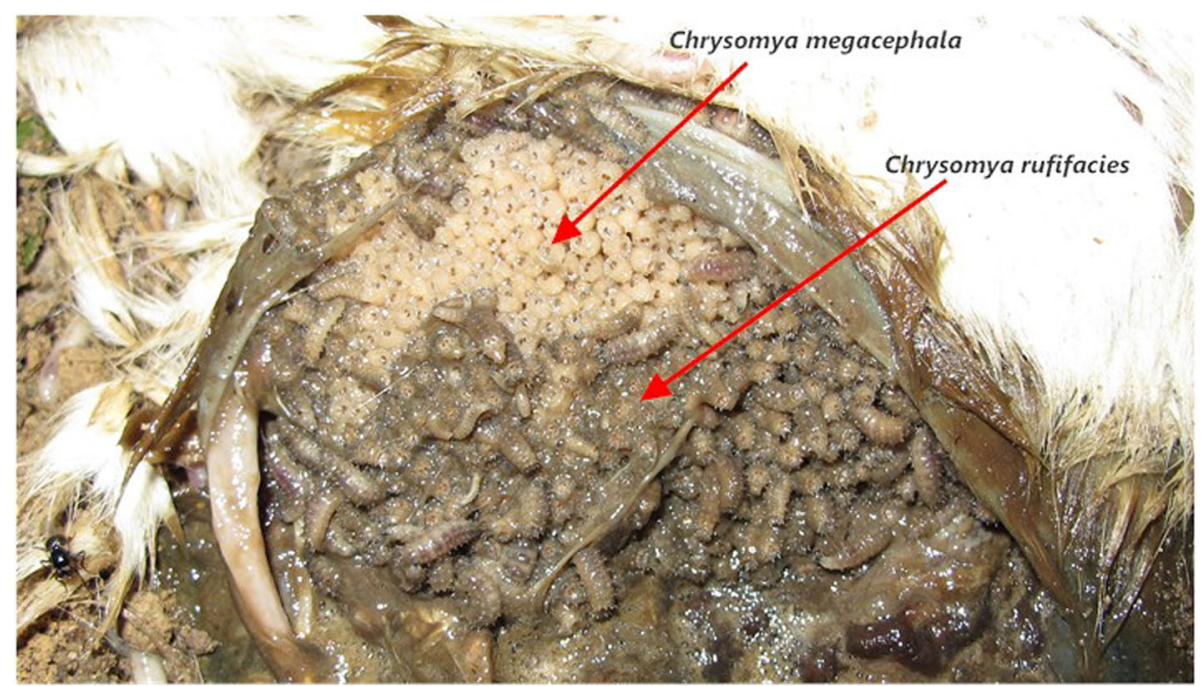

Fig. 2 Image showing species-specific aggregation of Ch. rufifacies and Ch. megacephala in rat carcass

instar larvae and prolonged until the post-feeding larvae withdrawn from the carcass. Aggregation temperature was also found correlated to depth $r(188)=0.21, p<0.05$, but not to volume $r(188)=0.104, p=0.28$ (Fig. 3). No correlation was also observed between aggregation temperature and ambient temperature $r(188)=0.01, p=0.885$ and relative humidity $r(188)=0.07, p=0.35$ (Fig. 3).

\section{Discussions}

Continuous records of carcass temperature during decomposition have shown two obvious elevation points. The first elevation is due to internal bacterial activities during putrefaction while the second elevation is related to maggot aggregation. Temperature reading in the second elevation is more significant as it occurred in a longer duration, has higher temperature range, and carcass-dependent. It was evident that at the beginning of death, temperature change pattern is similar regardless of carcass size, but it was different after $50 \mathrm{~h}$ of decomposition. Temperature after this period significantly associated with the heat produced by maggot aggregation. It was mentioned that maggot mass temperatures were elevated independently, not influenced by ambient temperatures after $69 \mathrm{~h}$ of decomposition (Joy et al. 2002). In a forensic postmortem, estimation of PMI after $72 \mathrm{~h}$ is more challenging as many internal and external factors are being involved (Henssge et al. 1995).One known external factors is the presence of maggot aggregation. Therefore, PMI estimation is more difficult after this time when actual temperature history where larvae developed is fluctuated depending on mass volume and its thermal generation. Their temperature can be over $20^{\circ} \mathrm{C}$ above ambient which could accelerate the growth rate of flies (Turner and Howard 1992; Catts and Goff 1992).
In this study, carcass temperatures were varied depending on the size of the carcass. Higher body temperature in macaque carcass could be due to the fact that aggregation temperature is a function of the volume and larva number (Johnson and Wallman 2014; Heaton et al. 2014). A bigger carcass could provide a large area for aggregation and support a higher number of larvae making more heat be produced. Besides generating higher temperature, the big carcass had also lost weight faster. This finding is similar to a pig decomposition study in Hawaii (Hewadikaram and Goff 1991).The study mentioned that decomposition occurs more quickly in more massive pig because it has attracted more flies and supports a more significant number of feeding larvae (Hewadikaram and Goff 1991).

The volume of aggregation was not found correlated to aggregation temperature. This result demonstrated a disagreement with laboratory maggot study from a cultured colony (Johnson and Wallman 2014; Charabidze et al. 2011). This inconsistency could be due to the dynamicity of larvae in the aggregation in the carcass that makes it difficult to be measured accurately. Unlike in a laboratory setup, maggot mass in the carcass is dynamic and possesses three-dimensional arrangements with various depth, width, and area. Therefore, accurate calculation of volume is critical. However, in an outdoor maggot study in pig carcass, a relationship of volume to aggregation temperature was found, but this is only valid to selected aggregations which were tightly packed and able to retain metabolic heat (Slone and Gruner 2007). Due to this limitation, computed tomography scanning was introduced as a new measurement method for volume and temperature on a deceased person (Johnson et al. 2012, 2013). 


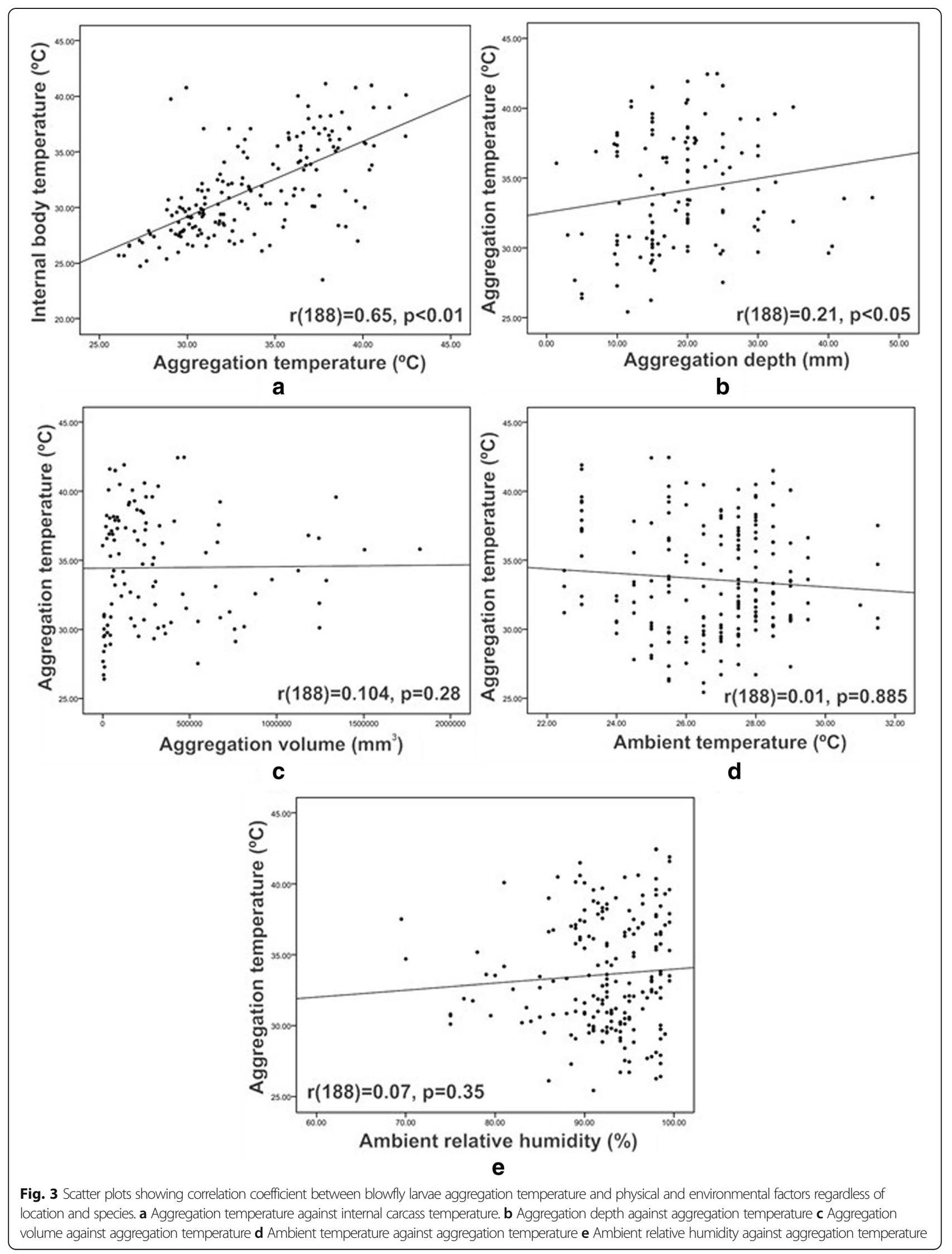


Researchers have shown that the temperature in maggot mass is a product of ambient temperature during the initial $24 \mathrm{~h}$ of larval development, but not when the maggot is in the second and third instar (Peters 2003; Joy et al. 2002). Larva at a later stage could generate sufficient heat through aggregation, therefore terminating its dependency to the ambient temperature. Aggregation temperature in our study showed no correlation with ambient temperature and relative humidity, therefore supporting the fact that larvae were able to regulate their temperature for survival. This microclimate can, however, increase metabolic rate and accelerate growth. Thus it should be, therefore, critical for minimum PMI estimation.

During feeding stage, larvae are more concentrated at the soft tissue of carcass primarily at the abdomen and genitalia. Various species of feeding blowfly larvae were found to share their food in the early stage of death as there are plenty of soft tissues and less competition. During this time, a clear boundary species-specific aggregation was observed. This behavior is not unusual, and it is believed can benefit larvae by sharing salivary enzymes, regulating developmental temperature and protection from predator and parasites. Species-specific aggregation was found in two blowfly species Chrysomya albiceps (Weidemann) and Chrysomya marginalis (Weidemann) (Richards et al. 2009). Although this behavior is not fully understood, we hypothesized that this could be related to larva ability to detect chemical signals or attractant of their species. The previous study noted that Lucilia sericata could identify the larva-crawled area and stay within the aggregation (Boulay et al. 2015). This unique aggregation behavior is not prolonged. After food sources become limited, species-specific aggregation of Ch. megacephala ceased, taken over by Ch. rufifacies. Predation of Ch. rufifacies larvae has frequently been reported in the literature (Chin et al. 2009; Goodbrod and Goff 1990).

Ch. rufifacies aggregation temperatures were found higher than Ch. megacephala in most measurements. This species, also noted, could generate higher temperature than Calliphora vicinal (Johnson et al. 2014). Variation temperature between species could support the theory that aggregation temperature is species-specific where similar species have been shown to aggregate at the same temperature (Aubernon et al. 2016). The previous study has noted that $L$. sericata has aggregation temperature of around $33.3{ }^{\circ} \mathrm{C}$ while Calliphora vomitoria and Calliphora vicina were around $29.6^{\circ} \mathrm{C}$ and $22.4{ }^{\circ} \mathrm{C}$, respectively (Aubernon et al. 2016). We hypothesized that temperature difference between $\mathrm{Ch}$. rufifacies and Ch. megacephala could be due to a species-specific factor. Besides that, hairy morphology and larva size of Ch. rufifacies which is relatively larger than Ch. megacephala might be the second reason for the higher heat produced by Ch. rufifacies during aggregation in our study. The relationship between larval size and temperature generation was previously demonstrated by a comparative study between Sarcophaga bullata (Sarcophagidae) and Protophormia terraenovae (Calliphoridae) (Rivers et al. 2010). Larval size is not only correlated to aggregation temperature but also has been found to correlate with their food quality, growth quality, and survival rate (Aubernon et al. 2016).

In our study, the highest numbers of aggregation were located under macaque carcass which was composed of third instar Ch. rufifacies. Ch. rufifacies larvae tend to stay under carcass until emerging rather than migrating away from the carcass. Research has shown that movement of Ch. rufifacies is nonrandom as they select the hottest spot in aggregation (Johnson et al. 2014). This strategy is believed as an effective way to protect them from unfavorable surrounding temperature and predation.

Based on our findings, locations primarily under carcass is the most suitable area that can give protection to larvae from cold air temperature, direct sunlight, and rainfall. Therefore, in a PMI estimation, measurement of multiple locations in a dead body at a death scene is crucial, and temperature measurements under a dead body should be given a priority as it could contains more packed aggregations. Infrared imaging is a useful choice to perform this measurement as it can effectively locate larva aggregation and measures the temperature without disturbing a dead body.(Johnson and Wallman 2013).

\section{Conclusions}

Although the findings obtained from this study were based on selected larval aggregations, the results have demonstrated the effect of corpse size, aggregation location, and species on the aggregation temperature of two well-known forensically important Malaysian blowflies. Based on the results of this study, larva aggregation location and its temperature in a corpse are critical in forensic entomology, and these aspects should be taken into consideration when handling a forensic investigation of decaying body. However, further fieldwork is needed to extend understanding of maggot mass thermoregulation and larva behavior in a dead body.

\section{Acknowledgements \\ This work was conducted with the help of the Malaysian Wild Life Department and National Parks of Malaysia (PERHILITAN) who gave permission to use macaques as animal model and also helped in handling and euthanizing all of the animals based on the approved animal ethic.}

Funding

No funding

Availability of data and materials

Data is available. 


\section{Authors' contributions}

AA was responsible for the conception and design of study, data collection, data analysis and interpretation of data, and drafting and writing the manuscript. $\mathrm{BO}$ contributed in data analysis, revising the manuscript critically for important intellectual content, and the approval of the version of manuscript for publication. Both authors read and approved the final manuscript.

\section{Authors' information}

AA obtained a PhD degree in Biomedical Sciences from Universit Kebangsaan Malaysia and currently a senior lecturer at the Faculty of Pharmacy, Universiti Teknologi Mara (UiTM) Selangor, Malaysia. His major interest is in carrion ecology and forensic entomology.

$\mathrm{BO}$ is a professor in entomology at the Faculty of Health Sciences, Universiti Kebangsaan Malaysia, Kuala Lumpur. He is a leading expert in forensic entomology in Malaysia.

\section{Ethics approval and consent to participate}

The research fulfilled animal ethic guidelines as approved by Animal Ethic Committee, Faculty of Medicine, Universiti Kebangsaan Malaysia (UKMAEC No: FSKB/2010/Baharudin/17- March/297-March-2010-April-2012). Consent to participate is not applicable.

\section{Consent for publication}

Not applicable

\section{Competing interests}

The authors declare that they have no competing interests.

\section{Publisher's Note}

Springer Nature remains neutral with regard to jurisdictional claims in published maps and institutional affiliations.

\section{Author details}

'Faculty of Pharmacy, Universiti Teknologi MARA, 42300 Bandar Puncak Alam, Selangor, Malaysia. ${ }^{2}$ Faculty of Health Sciences, Universiti Kebangsaan Malaysia, Jalan Raja Muda Abdul Aziz, 50300 Kuala Lumpur, Malaysia.

Received: 19 April 2017 Accepted: 7 November 2018

\section{Published online: 21 November 2018}

\section{References}

Anderson GS, VanLaerhoven SL (1996) Initial studies on insect succession on carrion in southwestern British Columbia. J Forensic Sci 41:617-625

Aubernon C, Boulay J, Hedouin V, Charabidze D (2016) Thermoregulation in gregarious dipteran larvae: evidence of species-specific temperature selection. Entomol Exp Appl 160(2):1-8

Azwandi A, Abu Hassan A (2009) A preliminary study on the decomposition and dipteran associated with exposed carcasses in an oil palm plantation in Bandar Baharu, Kedah, Malaysia. Trop Biomed 26(1):1-10

Boulay J, Betremieux C, Hedouin V, Charabidze D (2015) A first insight into the scanning behaviour of the presocial blow fly larvae. Physiol Entomol 40(4): 317-324

Byrd JH, Butler JF (1998) Effects of temperature on Sarcophaga haemorrhoidalis (Diptera: Sarcophagidae) development. J Med Entomol 35:694-698

Campobasso CP, Vella GD, Introna F (2001) Factors affecting decomposition and Diptera colonization. Forensic Sci Int 20:18-27

Catts EP, Goff ML (1992) Forensic entomology in criminal investigations. Annu Rev Entomol 37:253-272

Charabidze D, Bourel B, Gosset D (2011) Larval-mass effect: characterisation of heat emission by necrophageous blowflies (Diptera: Calliphoridae) larval aggregates. Forensic Sci Int 211(1-3):61-66

Chin HC, Ahmad NW, Lim LH, Jeffery J, Omar B (2009) Predation on pupa of Chrysomya rufifacies (Macquart) (Diptera: Calliphoridae) by parasitoid, Exoristobia philippinensis Ashmead (Hymenoptera: Encyrtidae) and Ophyra spinigera larva (Diptera: Muscidae). Trop Biomed 26:369-372

Goff ML (2000) A fly for the prosecution. Harvard University Press, Cambridge, p 240

Goodbrod JR, Goff ML (1990) Effects of larval population density on rates of development and interactions between two species of Chrysomya (Diptera: Calliphoridae) in laboratory culture. J Med Entomol 27:338-343

Greenberg B (1991) Flies as forensic indicators. J Med Entomol 28:565-577
Greenberg B, Kunich JC (2002) Entomology and the law. Flies as forensic indicators. Cambridge University Press, Cambridge, p 306

Heaton V, Moffatt C, Simmons T (2014) Quantifying the temperature of maggot masses and its relationship to decomposition. J Forensic Sci 59(32):1-7

Henssge C, Madea B, Knight B, Nokes L, Krompecher T (1995) The estimation of the time since death in the early postmortem interval. Arnold, London p. 262

Hewadikaram K, Goff ML (1991) Effect of carcass size on rate of decomposition and arthropod succession patterns. Am J Forensic Med Pathol 12:235-240

Johnson A, Archer M, Leigh-Shaw L, Brown M, O'Donnell C, Wallman J (2013) Non-invasive visualisation and volume estimation of maggot masses using computed tomography scanning. Int J Legal Med 127(1):185-194

Johnson A, Archer M, Leigh-Shaw L, Pais M, O'Donnell C, Wallman J (2012) Examination of forensic entomology evidence using computed tomography scanning: case studies and refinement of techniques for estimating maggot mass volumes in body. Int J Legal Med 126(5):693-602

Johnson A, Wighton SJ, Wallman JF (2014) Tracking movement and temperature selection of larvae of two forensically important blowfly species within a "maggot mass". J Forensic Sci 59(6):1586-1591

Johnson AP, Wallman JF (2013) Infrared imaging as a non-invasive tool for documenting maggot mass temperatures. Aust J Forensic Sci 46(1):73-79

Johnson AP, Wallman JF (2014) Effect of massing on larval growth rate. Forensic Sci Int 241:141-149

Joy JE, Herrell ML, Rogers PC (2002) Larval fly activity on sunlit versus shaded raccoon carrion in southwestern West Virginia with special references to the black blowfly (Diptera: Calliphoridae). J Med Entomol 39:392-397

Kurahashi H, Benjaphong N, Omar B (1997) Blowflies (insect: Diptera: Calliphoridae) of Malaysia and Singapore. Raffles Bull Zool 45(5):88-91

Omar B (2002) Key to third instar larvae of flies of forensic importance in Malaysia. In: Greenberg B, Kunich JC (eds) Entomology and the law: flies as forensic indicators. Cambridge University Press, Cambridge, pp 120-127

Peters SL (2003) The temperature variations of Dipteran larval masses analyzed on Florida black bear carcasses. Master of Science: University of Florida, Gainesville

Richards CS, Price BW, Villet MH (2009) Thermal eco-physiology of seven carrionfeeding blowflies (Diptera: Calliphoridae) in South Africa. Entomol Exp Appl 131:11-19

Rivers DB, Ciarlo T, Spelman M, Brogan R (2010) Changes in development and heat shock protein expression in two species of flies (Sarcophaga bullata [Diptera: Sarcophagidae] and Protophormia terraenovae [Diptera: Calliphoridae]) reared in different sized maggot masses. J Med Entomol 47: 677-689

Rumiza AR, Osman K, Ismail MI, Zuha RM, Abu Hassan R (2008) Determination of malathion levels and the effect of malathion on the growth of Chrysomya megacephala (Fibricius) in malathion-exposed rat carcass. Trop Biomed 25(3): 184-190

Shean BSL, Messinger L, Papworth M (1993) Observations of differential decomposition on sun exposed $\mathrm{v}$. shaded pig carrion in coastal Washington state. J Forensic Sci 38:938-949

Slone D, Gruner S (2007) Thermoregulation in larval aggregations of carrionfeeding blow flies (Diptera: Calliphoridae). J Med Entomol 44:516-523

Turner B, Howard T (1992) Metabolic heat generation in dipteran larval aggregations: a consideration for forensic entomology. Med Vet Entomol 6 : $179-181$

Zuha RM, Ankasha SJ, Disney RHL, Omar B (2016) Indoor decomposition study in Malaysia with special reference to the scuttle flies (Diptera: Phoridae). Egypt $J$ Forensic Sci 6(3):216-222 